\title{
Respectful maternity care in Ethiopian public health facilities
}

Ephrem D. Sheferaw ${ }^{1 *}$, Eva Bazant ${ }^{2}$, Hannah Gibson ${ }^{1}$, Hone B. Fenta ${ }^{3}$, Firew Ayalew', Tsigereda B. Belay ${ }^{1}$, Maria M. Worku', Aelaf E. Kebebu', Sintayehu A. Woldie', Young-Mi Kim², T. van den Akker ${ }^{5}$ and Jelle Stekelenburg ${ }^{6,7}$

\begin{abstract}
Background: Disrespect and abuse of women during institutional childbirth services is one of the deterrents to utilization of maternity care services in Ethiopia and other low- and middle-income countries. This paper describes the prevalence of respectful maternity care (RMC) and mistreatment of women in hospitals and health centers, and identifies factors associated with occurrence of RMC and mistreatment of women during institutional labor and childbirth services.
\end{abstract}

Methods: This study had a cross sectional study design. Trained external observers assessed care provided to 240 women in 28 health centers and hospitals during labor and childbirth using structured observation checklists. The outcome variable, providers' RMC performance, was measured by nine behavioral descriptors. The outcome, any mistreatment, was measured by four items related to mistreatment of women: physical abuse, verbal abuse, absence of privacy during examination and abandonment.

We present percentages of the nine RMC indicators, mean score of providers' RMC performance and the adjusted multilevel model regression coefficients to determine the association with a quality improvement program and other facility and provider characteristics.

Results: Women on average received 5.9 (66\%) of the nine recommended RMC practices. Health centers demonstrated higher RMC performance than hospitals. At least one form of mistreatment of women was committed in 36\% of the observations (38\% in health centers and 32\% in hospitals).

Higher likelihood of performing high level of RMC was found among male vs. female providers $(\hat{\beta}=0.65, p=0.012)$, midwives vs. other cadres $(\hat{\beta}=0.88, p=0.002)$, facilities implementing a quality improvement approach, Standardsbased Management and Recognition $\left(\mathrm{SBM}-\mathrm{R}^{\mathrm{O}}\right)(\hat{\beta}=1.31, p=0.003)$, and among laboring women accompanied by a companion $\hat{\beta}=0.99, p=0.003)$. No factor was associated with observed mistreatment of women.

Conclusion: Quality improvement using SBM- $R^{\odot}$ and having a companion during labor and delivery were associated with RMC. Policy makers need to consider the role of quality improvement approaches and accommodating companions in promoting RMC. More research is needed to identify the reason for superior RMC performance of male providers over female providers and midwives compared to other professional cadre, as are longitudinal studies of quality improvement on RMC and mistreatment of women during labor and childbirth services in public health facilities.

Keywords: Respectful maternity care, Mistreatment of women, Labor and delivery, Birth companion, Birth positioning, Ethiopia, Health facility

\footnotetext{
* Correspondence: Ephrem.Daniel@jhpiego.org

${ }^{1} \mathrm{~J}$ hpiego, Addis Ababa, Ethiopia

Full list of author information is available at the end of the article
} 


\section{Plain English summary}

Disrespect and abuse of women during institutional childbirth services is one of the deterrents to utilization of maternity care services in Ethiopia and other low- and middle-income countries. This paper describes the level of respectful maternity care (RMC) and mistreatment of women reported by women who gave childbirth in health facilities in Ethiopia, and identifies associated factors.

Trained external observers assessed care provided to 240 women in 28 health centers and hospitals during labor and childbirth using structured observation checklists. The outcome variable, providers' $R M C$ performance, was measured by nine behavioral descriptors. The outcome, any mistreatment of women, was measured by four items indicative of mistreatment of women: physical abuse, verbal abuse, absence of privacy during examination and abandonment.

Women on average received six of the nine recommended RMC practices. Health centers demonstrated higher RMC performance than hospitals. Any form of mistreatment of women was committed in more than two-thirds of the observations. Higher likelihood of performing high level of RMC was found among male providers vs. female, midwives vs. other cadres, facilities implementing a quality improvement approach, Standards-based Management and Recognition (SBM$\mathrm{R}^{\odot}$ and among laboring women accompanied by a companion. No factor was associated with observed mistreatment of women during institutional labor and childbirth services. Quality improvement using SBM- ${ }^{\odot}$ and having a companion during labor and delivery were associated with RMC. Policy makers need to consider the role of quality improvement approaches and accommodating companions in promoting RMC. More research is needed to identify the reason for superior RMC performance of male providers over female providers and midwives compared to other professional cadre.

\section{Background}

Following the growing evidence on women's experience of mistreatment of women during pregnancy and childbirth across the globe, the World Health Organization (WHO) released a statement on prevention and elimination of disrespect and abuse (D\&A) during facilitybased childbirth [1]. The statement advocates for governments and development partners to initiate, support and sustain programs designed to address quality of Maternal and Newborn Health $(\mathrm{MNH})$ services with a strong emphasis on the provision of respectful maternity care (RMC) as an essential component of quality of care [1]. The White Ribbon Alliance defines $\mathrm{RMC}$ as an approach that emphasizes the positive interpersonal interactions of women with health care providers and staff during labor, delivery, and the postpartum period. Absence of D\&A by health care providers and other staff alone is not sufficient for provision of RMC; the RMC definition calls for fostering positive staff attitudes and behaviors that are conducive to improved satisfaction of women with their birth experience [2]. Assessing the status of mistreatment of women in health facilities will inform programs engaged in promotion of RMC without losing sight in reducing mistreatment of women.

In Ethiopia, the proportion of childbirths attended by a Skilled Birth Attendant (SBA) in 2014 was 15\%, compared to $50-53 \%$ in other Sub-Saharan African countries, especially in East Africa [3, 4]. In many countries, one of the reasons for low rate of childbirth assisted by SBA is absence of RMC and the actual and perceived high D\&A committed by health providers [5-8]. As elsewhere, in Ethiopia, D\&A is a deterrent to women seeking childbirth in health facilities. A 2014 synthesis of evidence from 65 studies on the barriers of facility-based delivery in low-and middle-income countries showed many individual, community, and health system related factors, including mistreatment of women, geographic accessibility, health care costs, perceptions of quality, cultural and personal preferences, and education, contributed to low SBA rates [8]. This synthesis also noted that health professionals working at health facilities were not sensitive to women's privacy and showed little care in giving them psychological support when women requested it $[8,9]$. A 2014 study conducted in Addis Ababa at two health centers and one university teaching hospital found that $78 \%$ of women reported having experienced some form of D\&A [10]. There was also discrepancy between hospitals and health centers.

The Ethiopian Ministry of Health is highly committed to increasing the rate of SBA-assisted deliveries in health facilities; their health sector transformation plan (HSTP) has a target of $90 \%$ skilled birth attendance rate and a reduction of the maternal mortality ratio (MMR) from 420/100,000 live births in 2015 to 199/100,000 live births by 2020 [11]. The focus in the Health Sector Development Plans III and IV (implemented during 2005-2014) to achieve a higher rate of attended births at health facilities and a reduced MMR was mainly focused on bringing services closer to the community. Ethiopia's Ministry of Health acknowledges, however, that provision of RMC is also a key intervention to bring unreached women to health facilities for maternity care services and thus, an important component in achieving their 2020 goals. To date, some efforts have been made to integrate $\mathrm{RMC}$ in the in-service training packages for MNH care, particularly Basic Emergency Obstetrics and Newborn Care (BEmONC) training. The BEmONC training package encourages providers to deliver services 
that are acceptable to women, that empower women and their families to become active participants in care, protect the rights of women, ensure that all healthcare staff use positive interpersonal communication with women and companions and promote provision of emotional, psychological, and social support to women [12].

This analysis draws on data from a larger study designed to assess the Standards-Based Management and Recognition $\left(S B M-R^{\odot}\right)$ quality improvement approach that was implemented for two years in Ethiopia. SBM- $R^{\odot}$ is a quality improvement approach developed by Jhpiego that sets evidence-based performance standards and then empowers health-care managers and providers to assess and address gaps between actual and desired performance at their facility [13]. The SBM- $R^{\odot}$ approach to quality improvement comprises four steps:1) defining evidence-based and locally relevant standards 2) assessing the gap between desired and actual performance, designing and implementing interventions to close this gap within health facilities3) periodically measuring progress towards desired performance and 4) rewarding performance [14-17].

The objectives of this manuscript are a) to measure the prevalence of RMC and mistreatment of women in hospitals and health centers and b) to identify factors associated with the observed RMC and mistreatment of women in Ethiopia, including facility- and providerrelated factors.

\section{Methods}

\section{Study design}

This study used data form the SBM- ${ }^{\odot}$ quality improvement approach evaluation. This analysis used crosssectional data combining both SBM- $\mathrm{R}^{\odot}$ intervention and matched comparison sites. This manuscript focused on the observation of care data and in particular, the respectful maternity care elements.

\section{Study setting}

Ethiopia uses a three-tier health structure of primary, secondary and tertiary levels. The primary level includes health centers with their satellite health post and primary hospitals. In the secondary and tertiary level, general hospitals and specialized hospitals are included [11].

Maternal and Child Health Integrated Program (MCHIP) implemented by Jhpiego used SBM- $\mathrm{R}^{\odot}$ as part of a comprehensive package of interventions aimed at improving quality of maternal and newborn health including RMC in Ethiopia for two years between 2002 and 2003. The study was conducted in the four regions of the country namely, Tigray, Amhara, Oromia and SNNP regions. A total of 28 urban and peri-urban health facilities six referral hospitals and 22 health centers were selected.
Half of the facilities participated in the study (three hospitals and eleven health centers) had implemented SBM- ${ }^{\odot}$ approach.

\section{Sample size}

The unit of analysis for this study was each observation, which represents a unique woman. Providers may have cared for multiple women during the observation period. Sample size for labor and delivery observation in the larger $S B M-R^{\odot}$ evaluation study was calculated to detect a minimum of $20 \%$ difference in performance of Active Management of Third Stage of Labor (AMSTL) between SBM- $\mathrm{R}^{\odot}$ intervention and comparison facilities, with $80 \%$ statistical power, $95 \%$ level of confidence and the recommended value of $1 \%$ intraclass correlation coefficient for median value of primary health care research [18]. The performance of AMSTL for comparison sites was set as $29 \%$ using a previous MCHIP quality of care study [19]. The final sample size was 240 women. A total of 117 providers who were on duty during data collection period were invited for observation. All women who came for labor and delivery and postnatal care were invited for observation.

\section{Data collection}

The study used a structured observation of the providerclient interaction during normal labor and delivery services. Trained assessors were clinicians (bachelor and master's degree level midwives and health officers) and national level BEmONC trainers who were external to the facility, recruited from regions other than their own. Each assessor went through a one-week study training workshop. Data were collected in July and August, 2014. Assessors observed midwives, nurses and health officers who were providing labor and delivery services during day and night. The assessors were not intervening with the care provided to women. In an event where the assessor deemed the safety or life of the mother or newborn in danger, or where the client's status was deteriorating, the assessors were trained to alert a senior clinician to intervene. The observation of women started in the second stage of labor and continued to two hours post-delivery. Two assessors were assigned per facility and each covered two eight hour shifts per day. In each health facility between two and 11 women were observed within two to five days. In 16 of the facilities assessed, 11 women were observed; in the remaining 12 health centers, between two and nine women were observed. The median number of women observed per facility was 11 .

\section{Data quality}

To ensure data quality, the study coordinator oversaw the data collection process, closely communicating with 
the principal investigator and supervisors. Each day, supervisors checked the completeness of observational data collected.

\section{Measures}

The two outcomes of interest (dependent variables) were 'any mistreatment of women' and total number of RMC descriptors practiced by providers. Each element comprising these outcome measures was recorded as dichotomous (observed or not observed). The providers' mistreatment of women and RMC structured observation checklist was adapted from the MCHIP quality of care checklist. The larger study was validated in five countries, including Ethiopia [20].

The structured RMC observation checklist included 9 items that described desirable provider behaviors. The desirable provider behaviors included: (1) receiving and greeting the pregnant women, (2) explaining each step of the examination, (3) encouraging women to ask questions, (4) responding to women and their companions politely when they asked questions, (5) explaining to women what will happen in labor, (6) encouraging women to walk and change position, (7) ensuring light eating, (8) asking women which position they would like to deliver in and (9) allowing women to give birth in the position they want. The outcome variable was the sum of the nine equally weighted RMC behaviors practiced for each observation and ranged from 0 to 9 .

The undesirable provider behaviors reflecting mistreatment of women included 4 items: (1) physical abuse (slapping or hitting women during labor), (2) verbal abuse (making insults or threatening women and or their companions), (3) the absence of privacy during examination and (4) abandonment (leaving women alone during labor). In the Bohren et, al. (2015) typology of mistreatment of women during childbirth, the four items are mapped with four of the seven third-ordered themes [21]. The outcome variable, 'any mistreatment of women' was dichotomous requiring a 'yes' or 'no' response. 'Yes' was marked if any of the above behaviors was observed. RMC ranged between 0 and $100 \%$.

\section{Data management and analysis}

Cleaned observation data were entered twice into CS Pro 5.0 [22]. Data discrepancies were resolved and the data were exported to STATA 13.0 for further analysis [23].

Chi square test for categorical variables were used to compare health workers' practice of mistreatment of women with facility types (health centers and hospitals). Independent samples $t$-test were used to compare health workers' RMC practices with facility types. Sociodemographic characteristics of observed health workers and facility characteristics were reported using frequency and percentage disaggregated by facility type. Tests of proportions and relationships between mistreatment of women, RMC and socio-demographic variables were computed at $5 \%$ level of significance.

Multivariable, multilevel linear regression for the continuous outcome variable, total RMC score, and multivariable, multilevel logistic regression analysis for the categorical outcome, any mistreatment of women, were used because observation data are hierarchical (i.e. clients are nested within providers, providers are nested with in health facilities). Also, the use of flat (non-clustered) models could underestimate the standard errors of the effect sizes, which consequently can affect decision on null hypothesis. In such data, women observed within same health facility may be more similar to each other than women observed in other health facilities.

Three steps were used to fit multilevel logistic regression and multilevel linear regression models. First, the null, unadjusted model (without predictors) helped determine whether multilevel modeling was needed. Second, bivariate logistic and linear regression models were fitted to identify potential predictors of occurrence of mistreatment of women and practice of RMC for multivariable analysis. Third, multivariable logistic and linear regression models were fitted to identify predictors of occurrence of mistreatment of women and practice of RMC. The interclass correlation coefficients (ICC) for the null model and multivariable model were calculated and used to evaluate the variations explained by facility and provider cluster effects on the outcome variables [24]. For selection of candidate variables for the multivariate model, $p$-value of less than 0.25 was used.

The fixed effect sizes of individual and facility-level factors on the total RMC scores were expressed using regression coefficient $(\beta)$, adjusted regression coefficients $(\hat{\beta})$, the $95 \%$ Confidence Interval (CI) and $p$-values. Whereas, the fixed effect sizes of individual and facilitylevel factors on the observed practice of mistreatment of women were expressed using the crude odds ratio (COR), adjusted odds ratio (AOR), the $95 \%$ Confidence Interval $(\mathrm{CI})$ and $p$-values.

\section{Ethics}

The study protocol was reviewed and approved by the National Ethics Review Committee (NERC) at the Ministry of Science and Technology in Ethiopia. The Johns Hopkins Bloomberg School of Public Health Institutional Review Board in Baltimore, Maryland, USA, indicated the study was exempt from oversight under U.S. legislation, 45 CFR 46.101(b). Recruitment of women and consent process were conducted immediately after arrival at the facility. In this study, each woman interviewed, observed and each provider observed gave informed written consent prior to participation. 


\section{Results}

We observed 240 women (175 in health center and 65 in hospitals) during labor and childbirth. The observed deliveries were managed by 117 providers in 28 facilities. An average of two women were observed per provider (range of one to eight). The median number of women observed per facility was 11 .

Females provided care in three-fourths of the observations $(73 \%$ or $n=174)$. Most observations were of deliveries with midwives $(78 \%, n=187)$, and midwife-assisted deliveries were observed more in hospitals than health centers $(94 \%$ vs. $72 \%, p<0.001)$. Health workers allowed a support person during labor in $84 \%$ of observations (86\% in health centers and $81 \%$ in hospitals) (Table 1).

As shown in Table 2, the observations were conducted in 28 health facilities ( 22 health centers and 6 hospitals). The health centers included for the observation had an average of 646 annual deliveries and the hospitals had an average of 1,974 annual deliveries. On average, health centers had 5.5 beds with a standard error of 0.3 whereas hospitals had 159 beds with a standard error of 4.9. Health centers had an average of $5.8 \mathrm{MNH}$ staff with a standard error of 0.2 and hospitals had an average of $17 \mathrm{MNH}$ staff with a standard error of 0.3 .

\section{Prevalence of respectful maternity care}

The most frequently practiced RMC element was ensuring that women take light food, occurring in $83 \%(n=$ 193) observations. The least practiced item was asking women's preference of birth position, observed in only $29 \% \quad(n=68)$ of the observations. Health centers performed better than hospitals in all nine practices and the differences were statistically significant in the following five practices: receiving and greeting women, encouraging women to ask questions, encouraging walking and changing positions, ensuring women have taken light food and allowing women to give birth in the position she prefers. On average 5.9 (66\%) of the 9 recommended RMC descriptors were performed; the average performance in health centers was significantly higher compared to health centers $6.2(69 \%)$ and in hospitals $5.3(59 \%), p=0.007$ (Table 3).

\section{Observed practice of mistreatment of women}

Of the total 240 observations, in $36 \%(n=87)$ at least one form of mistreatment of women was observed (Table 3). The element with the highest prevalence was abandonment or being left alone, 19\% $(n=43)$. Verbal abuse occurred in $8 \%(n=18)$ of the observations. No statistically significant difference was observed between hospitals and health centers in observed prevalence of these elements of mistreatment of women (Table 4).

Table 5 describes results from multivariate linear regression analysis of facility and provider related factors associated with total RMC score. Midwives were more likely to have higher total RMC score compared to other providers (nurses, health officers and doctors) $[\hat{\beta}=0.88,95 \% \mathrm{CI}$ (0.32, 1.44); $p=0.002]$. The coefficient was higher among male than female providers $[\hat{\beta}=0.65,95 \%$ CI $(0.15$, $1.16) ; p=0.012]$. Facilities that implemented SBM-R approach had a higher RMC score $[\hat{\beta}=1.31,95 \% \mathrm{CI}(0.434$, 2.19), $p=0.003$ ]. Women were more likely to have higher RMC scores when birth companions were allowed in labor and delivery rooms $[\hat{\beta}=0.99,95 \% \mathrm{CI}(0.335,1.63)$, $p=0.003)$. Health centers had a higher RMC score compared to hospitals, although this finding was not statistically significant.

Table 1 Characteristics of Labor and Delivery Observations, by Facility Type (Observations as the unit of analysis)

\begin{tabular}{|c|c|c|c|c|c|c|c|}
\hline & \multicolumn{2}{|c|}{ Total Observations } & \multicolumn{2}{|c|}{ Health Center observations } & \multicolumn{2}{|c|}{ Hospital observations } & \multirow[t]{2}{*}{$p$-value (Chi-Square) } \\
\hline & $\%$ & $\mathrm{~N}$ & $\%$ & $\mathrm{~N}$ & $\%$ & $\mathrm{~N}$ & \\
\hline \multicolumn{8}{|l|}{ Provider characteristics } \\
\hline \multicolumn{8}{|l|}{ Sex } \\
\hline Male & 27 & 65 & 32 & 55 & 15 & 10 & $0.009^{*}$ \\
\hline Female & 73 & 174 & 68 & 119 & 85 & 55 & \\
\hline \multicolumn{8}{|l|}{ Profession } \\
\hline Midwife & 78 & 187 & 72 & 126 & 94 & 61 & $<0.001^{*}$ \\
\hline Others (Nurse, doctor, health officers) & 22 & 53 & 28 & 49 & 6 & 4 & \\
\hline \multicolumn{8}{|l|}{ Region } \\
\hline Tigray & 18 & 44 & 13 & 22 & 34 & 22 & 0.864 \\
\hline Amhara & 27 & 65 & 37 & 65 & 0 & 65 & \\
\hline Oromiya & 28 & 66 & 25 & 44 & 25 & 22 & \\
\hline SNNPR & 27 & 65 & 25 & 44 & 25 & 21 & \\
\hline Support person allowed during labor & 84 & 195 & 86 & 144 & 78 & 51 & 0.179 \\
\hline
\end{tabular}

*. P-value significant at 0.05 level 
Table 2 Characteristics of Facilities Participated in Labor and Delivery Observations

\begin{tabular}{lllll}
\hline Facility characteristics & $\begin{array}{l}\text { Total }(N=28) \\
\text { mean }(\mathrm{SE})\end{array}$ & $\begin{array}{l}\text { Health Centers }(N=22) \\
\text { mean }(\mathrm{SE})\end{array}$ & $\begin{array}{l}\text { Hospitals }(N=6) \\
\text { mean }(\mathrm{SE})\end{array}$ & $p$-value (independent sample $t$-test) \\
\hline Annual deliveries & $1006(53)$ & $646(27)$ & $1974(97)$ & $\mathbf{0 . 0 1 \mathbf { 2 } ^ { * }}$ \\
Number of beds & $50(4.8)$ & $5.5(0.3)$ & $159(4.9)$ & $<\mathbf{0 . 0 0 1 *}^{*}$ \\
Number of MNH staff & $9(0.4)$ & $5.8(0.2)$ & $17(0.3)$ & $<\mathbf{0 . 0 0 1}^{*}$ \\
Number of BEmONC trained staff & $4(0.3)$ & $2.3(0.1)$ & $9(0.7)$ & 0.069 \\
\hline
\end{tabular}

*. P-value significant at 0.05 level

Table 6 shows results from multi-level multivariable logistic regression analysis of any mistreatment of women observed in labor and delivery observations as an outcome and provider's facility and provider characteristics variables as explanatory variables. None of the hypothesized provider and facility-related characteristics were associated with observed mistreatment of women.

\section{Discussion}

In this study, carried out in hospitals and health centers of four regions of Ethiopia, labors and births were observed. The analysis revealed the prevalence of RMC and mistreatment of women in hospitals and health centers and identified factors associated with the observed RMC and mistreatment of women.

\section{Respectful maternity care}

On average, a woman received two-thirds of the aspects of RMC assessed. We discuss some of the practices that were least likely to be observed in our study and showed significant variation between hospitals and health centers.

\section{Allowing women to choose preferred birthing position}

Providers' practice of allowing women to choose their preferred birth positioning occurred at the lowest frequency of all the desired behaviors; only about two in five women in health centers and one in five women in hospitals were given choices for delivery position. Quality statement 6.2 of the WHO standards for improving quality of maternal and newborn care in health facilities states that every woman should receive support to encourage her to adopt the position of her choice during

Table 3 Prevalence of RMC services during labor and delivery, by Facility Type, Ethiopia 2014 ( $N=240$ observations)

\begin{tabular}{|c|c|c|c|c|c|}
\hline \multirow[b]{2}{*}{ Provider: } & \multicolumn{2}{|c|}{ Total $(n=240)$} & \multirow{2}{*}{$\begin{array}{l}\text { Health Center }(n=175) \\
\%\end{array}$} & \multirow{2}{*}{$\begin{array}{l}\text { Hospital }(n=65) \\
\%\end{array}$} & \multirow[t]{2}{*}{$p$-value } \\
\hline & $\%$ & No. & & & \\
\hline ...receives and greets the pregnant women & 77 & 181 & 82 & 63 & $0.002 *$ \\
\hline Don't know or missing & 2 & 5 & 3 & 0 & \\
\hline ... explains each step of the examination to the women & 65 & 153 & 69 & 57 & 0.092 \\
\hline Don't know or missing & 3 & 6 & 3 & 0 & \\
\hline ...encourages the women to ask questions & 39 & 90 & 44 & 26 & $0.015^{*}$ \\
\hline Don't know or missing & 3 & 7 & 4 & 0 & \\
\hline ... responds to a women/companion question politely & 72 & 167 & 74 & 68 & 0.328 \\
\hline Don't know or missing & 4 & 9 & 5 & 0 & \\
\hline ...explains what will happen in labor to women & 81 & 188 & 78 & 88 & 0.107 \\
\hline Don't know or missing & 3 & 8 & 5 & 0 & \\
\hline ...encourages women to walk and change position & 69 & 162 & 73 & 59 & $0.027^{*}$ \\
\hline Don't know or missing & 3 & 6 & 3 & 0 & \\
\hline ... at least once ensures if she has taken light food & 83 & 193 & 87 & 73 & $0.011 *$ \\
\hline Don't know or missing & 3 & 8 & 3 & 3 & \\
\hline ... asks women which position she would like to deliver & 29 & 68 & 33 & 20 & 0.052 \\
\hline Don't know or missing & 3 & 8 & 5 & 0 & \\
\hline ... allowed to give birth in the position she wants & 38 & 85 & 42 & 27 & $0.029 *$ \\
\hline Don't know or missing & 6 & 15 & 8 & 2 & \\
\hline Average number of RMC Practices performed & 66 & 5.9 & 69 & 59 & $0.007^{*}$ \\
\hline
\end{tabular}

*. P-value significant at 0.05 level 
Table 4 Prevalence of mistreatment of women during labor and delivery, by Facility Type

\begin{tabular}{|c|c|c|c|c|c|c|c|}
\hline \multirow[b]{2}{*}{ Item } & \multicolumn{2}{|c|}{ Total } & \multicolumn{2}{|c|}{ Health Center } & \multicolumn{2}{|c|}{ Hospital } & \multirow[t]{2}{*}{$p$-value } \\
\hline & $\%$ & No. & $\%$ & No. & $\%$ & No. & \\
\hline Physical abuse & 9 & 21 & 9 & 15 & 10 & 6 & 0.973 \\
\hline Verbal abuse & 8 & 18 & 6 & 10 & 12 & 8 & 0.117 \\
\hline Privacy violated & 17 & 40 & 17 & 29 & 17 & 11 & 0.951 \\
\hline Abandonment: or being left alone & 19 & 43 & 19 & 32 & 17 & 11 & 0.745 \\
\hline \multicolumn{8}{|l|}{ Summary Outcome } \\
\hline $\begin{array}{l}\text { Any mistreatment of women: At least one } \\
\text { form of mistreatment of women }\end{array}$ & 36 & 87 & 38 & 66 & 32 & 21 & 0.436 \\
\hline
\end{tabular}

labor [25]. Bohren et al's [26] systematic review of barriers to institutional delivery found that being asked to adopt unfamiliar birthing positions and having no control over choice of birthing position are important reasons why some women prefer home deliveries. In our study, the practice of allowing preferred positions was significantly higher in health centers than in hospitals. A possible reason for this discrepancy may be the relatively higher client volumes and lower staff-to-patient ratios in hospitals, which may impede providers' ability to offer more individualized care. The low level of practice of allowing women to choose their preferred birthing position could be attributed to the fact that facilities usually do not have physical structures for alternative birth positions (i.e., suitable delivery couches or floor space for squatting positions). For example, a study in Afar region in Ethiopia showed women preferred a sitting position for delivery but delivery beds that have space for a semisitting position were not available [27]. Providers' lack of training on alternate birth positions, particularly during their pre-service practicum, may also explain why some do not allow women to deliver in their preferred position. Health workers in a study in Bangladesh and Uganda reported that they had not been trained to deliver women in positions other than lying at their backs and thus did not feel confident to do so [28, 29].

\section{Light eating}

A majority of women were permitted to take light food during labor and delivery, with health centers

Table 5 Factors Associated with Provision of RMC in Labor and Delivery in Bivariate and Multivariable Multi-level Regression Models (Observation): Outcome variable: Number of RMC practices performed

\begin{tabular}{|c|c|c|c|c|c|c|}
\hline \multirow[t]{2}{*}{ Predictor } & \multicolumn{3}{|l|}{ Bivariate } & \multicolumn{3}{|l|}{ Multivariate } \\
\hline & $\begin{array}{l}\text { Coefficient } \\
(\beta)\end{array}$ & $95 \% \mathrm{Cl}$ & $\overline{p \text {-value }}$ & $\begin{array}{l}\text { Adjusted } \\
\text { Coefficient }(\hat{\beta})\end{array}$ & $95 \% \mathrm{Cl}$ & $p$-value \\
\hline \multicolumn{7}{|l|}{ Cadre } \\
\hline Midwife (Ref: Others (Nurses, doctors, health officers) & 0.75 & $0.20,1.30$ & 0.007 & 0.88 & $0.32,1.44$ & $0.002^{*}$ \\
\hline \multicolumn{7}{|l|}{ Provider gender } \\
\hline Female (Ref: Male) & -0.44 & $-0.98,0.09$ & 0.107 & -0.65 & $-1.16,-0.15$ & $0.012^{*}$ \\
\hline \multicolumn{7}{|l|}{ Facility type } \\
\hline Health center (Ref: Hospital) & 0.94 & $-0.534,2.15$ & 0.237 & 0.92 & $-0.106,1.95$ & 0.079 \\
\hline \multicolumn{7}{|l|}{ QI Intervention status } \\
\hline Intervention (Ref: Comparison) & 1.29 & $0.25,2.34$ & 0.016 & 1.31 & $0.43,2.19$ & $0.003^{*}$ \\
\hline \multicolumn{7}{|l|}{ Companion encouraged } \\
\hline Yes (Ref: No) & 1.03 & $0.358,1.71$ & 0.003 & 0.99 & $0.335,1.63$ & $0.003^{*}$ \\
\hline \multicolumn{7}{|l|}{ Region } \\
\hline Amhara (Ref: Tigray) & 0.68 & $-0.94,2.31$ & 0.409 & & & \\
\hline Oromiya & -1.22 & $-2.9,0.46$ & 0.155 & & & \\
\hline SNNPR & -0.8 & $-2.37,0.77$ & 0.319 & & & \\
\hline Annual number of deliveries & -0.0002 & $-.001,0.0005$ & 0.553 & & & \\
\hline Number of MNH staff & -0.030 & $-0.134,0.074$ & 0.57 & & & \\
\hline Number of BEmONC trained staff & 0.026 & $-0.133, .186$ & 0.747 & & & \\
\hline
\end{tabular}

Notes. Provision of RMC services during labor and delivery was defined as mean percentage score on a total of 10 practices

Variables included in the multivariate are those with $p$-values of less than 0.25 at bivariate level

*. P-value significant at 0.05 level. OR, adjusted coefficient, $95 \% \mathrm{Cl}$, and confidence interval. Ref, reference group 
Table 6 Factors Associated with Any Mistreatment of Women in Labor and Delivery in Bivariate and Multivariable Multi-level Regression Models (Observation), $(n=240)$ : Outcome variable: Any Mistreatment of Women

\begin{tabular}{|c|c|c|c|c|c|c|}
\hline \multirow[t]{2}{*}{ Predictor } & \multicolumn{3}{|c|}{ Bivariate } & \multicolumn{3}{|c|}{ Multivariate } \\
\hline & COR & $95 \% \mathrm{Cl}$ & $\overline{p \text {-value }}$ & AOR & $95 \% \mathrm{Cl}$ & $p$-value \\
\hline \multicolumn{7}{|l|}{ Cadre } \\
\hline Midwife (Ref: Others (Nurses, doctors, health officers) & 0.48 & $0.15,1.57$ & 0.226 & 0.56 & $0.13,2.44$ & 0.441 \\
\hline \multicolumn{7}{|l|}{ Provider gender } \\
\hline Female (Ref: Male) & 0.85 & $0.29,2.49$ & 0.769 & & & \\
\hline \multicolumn{7}{|l|}{ Facility type } \\
\hline Hospital (Ref: Health center) & 0.65 & $0.06,7.22$ & 0.724 & & & \\
\hline \multicolumn{7}{|l|}{ Intervention status } \\
\hline Comparison (Ref: Intervention) & 5.41 & $0.80,5.41$ & 0.083 & 4.65 & $0.51,42.5$ & 0.174 \\
\hline \multicolumn{7}{|l|}{ Companion encouraged } \\
\hline Yes (Ref: No) & 0.422 & $0.11,1.60$ & 0.205 & 0.48 & $0.11,2.06$ & 0.324 \\
\hline Annual number of deliveries & 0.99 & $0.99,1.0$ & 0.126 & 1.00 & $0.99,1.0$ & 0.082 \\
\hline Number of beds & 0.99 & $0.97,1.01$ & 0.445 & & & \\
\hline Number of MNH staff & 0.98 & $0.81,1.20$ & 0.908 & & & \\
\hline Number of BEmONC trained staff & 0.73 & $0.51,1.03$ & 0.078 & 1.33 & $0.71,2.50$ & 0.368 \\
\hline \multicolumn{7}{|l|}{ Region } \\
\hline Amhara (Ref: Tigray) & 0.28 & $0.01,5.7$ & 0.408 & 0.23 & $0.01,5.08$ & 0.350 \\
\hline Oromiya & 8.24 & $0.41,165.8$ & 0.168 & 7.67 & $0.38,156.03$ & 0.185 \\
\hline SNNPR & 7.29 & $0.45,117.9$ & 0.162 & 10.88 & $0.62,192.17$ & 0.103 \\
\hline
\end{tabular}

Notes. Any mistreatment of women during labor and delivery was defined as mean percentage score on a total of 10 aspects. COR crude odds ratio, $A O R$ adjusted odds ratio, 95\% Cl confidence interval, Ref reference group

encouraging this more frequently than hospitals. The practice occurred much more frequently than in a previous study in Ethiopia in 2012 that reported only 40\% of women were allowed food or fluid intake during labor and delivery [20]. The reason for the higher rate in our study could be the result of exposure of providers to the inservice BEmONC training that includes an RMC session focused on interpersonal communication skill of providers, respecting culture, belief and values of clients [30].

\section{Birth companions}

Birth companions can improve experiences of women during labor and delivery; this is articulated in a statement by the World Health Organization [31]. One of the promising findings of this study was health workers' frequent practice of allowing a support person to be with women during labor. Four in five women were allowed to have a support person during labor, with no significant difference between health centers and hospitals. The finding was promising compared to another qualitative study, in Tanzania, that reported women felt ignored and neglected during child birth because family members or companions were not allowed to provide support [32]. Similarly, a study conducted in Jordan also revealed that women felt dissatisfied with the health system when they were not allowed to have a support person in delivery room [33].

\section{Provider and facility factors}

Several socio-demographic and health facility factors were found to be related to observed RMC practices. First, the type of health worker was significantly associated with provision of RMC care; midwives were better RMC service providers compared to nurses, health officers and doctors perhaps because their training focuses primarily on maternity care. In Ethiopia $\mathrm{MNH}$ service is provided by midwives, nurses, health officers and doctors. A Cochrane review on midwife-led models of care for childbirth in high income countries showed that midwife-led care was beneficial particularly for normalizing and humanizing childbirth [34].

Surprisingly, male providers were observed engaging in RMC practices more frequently than female providers. This finding is difficult to interpret and runs counter to stereotype of women being more empathic and caring than men. A clue from a study of nurses' abuse of patients in South Africa concluded that female nurses deployed violence against patients in their work as a means of creating social distance and maintaining fantasies of identity and power in their continuous struggle to assert their professional and middle class identity [5]. A literature review on barriers to quality midwifery care discussed the triple burdens faced by female midwives: (1) reproductive (childbearing), (2) productive 
(economic), and (3) community management (e.g. unpaid work in support of the community). The effect of social, economic and professional barriers resulted in moral distress and burn out, which may have led to abusive behavior [35]. The sex and professional disparity in the provision of RMC calls for strengthened intervention starting from teaching institutions, in-service training and health program administration to institutionalize provision of RMC by all providers male and female. This is also in line with MOH's health sector transformational agenda of creating a caring, respectful and companionate health professionals [36].

The third factor that affected provision of RMC was the presence of birth companion. Women were more likely to receive RMC when birth companions were allowed in labor. Presence of birth companions helped the women receive emotional and physical support and comfort from their loved ones, and removed some of the burden from health workers. Respondents in studies in Tanzania discussed how birth companions assisted and encouraged women, because providers were absent [32, 37]. The WHO Safe Birth checklist also mentions companions in the context of calling providers for help when needed [38].

The final factor that showed a significant relationship to the provision of RMC services was implementation of SBM- $R^{\odot}$ quality improvement approach; facilities that implemented the approach showed higher level of RMC compared to those who did not. SBM- $\mathrm{R}^{\odot}$ was one of the quality improvement approaches designed to promote RMC reviewed by Bowser and Hill in the 2010 landscape analysis exploring evidence for mistreatment of women in facility based childbirth [39]. Integrating RMC in quality improvement approaches is important in order to improve care for women. Experience of care is an integral part of the WHO's Quality of Care Framework for Maternal and Newborn Health [40] and RMC improves the experience of care.

\section{Mistreatment of women}

Article IV of the UN's universal rights of childbearing women document states that every woman has the right to be treated with dignity and respect [41]. In this study, more than a third of the women observed in delivery were not treated with respect, that is, they experienced at least one form of D\&A, defined as physical abuse, verbal abuse, violation of privacy and abandonment. In observational studies, physical abuse (slapping/hitting) is expected to be low because of a potential observer effect. In this observational study however, the level of D\&A was high compared to an exit interview of women conducted in four sub-counties and Nairobi, Kenya, which reported that $20 \%$ of women experienced any form of D\&A [42]. However, it was low compared to the prevalence of D\&A found in a study using exit interviews conducted in four health facilities in Addis Ababa, Ethiopia, in which $98 \%$ of women reported at least one form of D\&A [43, 44]. Given the similar cultural contexts, we believe that there might have been some observational effect reducing the prevalence from what it might have been had there been no observers, though one cannot rule out an actual effect of the intervention without further research designed to rule out observer effects.

Physical abuse (woman being slapped or hit) was reported in $9 \%$ of the observations. This is much higher than observations of care in Tanzania where $2.7 \%$ of women living with HIV and $4.7 \%$ of women who were not HIV positive were physically abused in labor [45]. Levels of observed physical abuse in this study were also higher than those reported by four client exit interview studies in sub-Saharan Africa [43, 46]. The reason for high rates of physical abuse even in the presence of an external observer was unexpected and needs further investigation as to why health workers are committing such actions. Part of the reason could be rationalization of physical abuse by health providers, with the belief to ensure safety of newborn. In a qualitative study conducted among midwifery students in Ghana and health workers in Nigeria, some students and health workers mentioned it was necessary to hit women to gain compliance $[47,48]$.

In this study, eight percent of women were verbally abused by health providers. This was a little higher than an observational study in a hospital in Tanzania, where providers used non-dignified language with $5.6 \%$ and shouted at $6.6 \%$ of HIV-negative women while taking their medical history [45]. An exit interview study conducted in Ethiopia and Kenya showed 14\% women in Addis Ababa hospitals [43] and 18\% of women in Kenya were verbally abused [42]. Reasons for health providers verbally abusing laboring women were not explored in this study but qualitative study in Tanzania suggested coming too early or too late for delivery, wearing old dirty dresses and not pushing strongly were some of the reasons why women were verbally abused by providers [32]. A study in Ghana with midwifery students revealed that both students and their preceptors do not know how to encourage women to push or to open their legs [48].

The rate of verbal abuse observed was less than in client exit interview reports [42] [43]. Much work is needed to eliminate verbal abuse by health providers; treating every woman with respect and dignity is a human right issue.

Though there were factors found to be related to positive treatment of women in labor, assessment of socio-demographic and institutional related factors on 
the observed mistreatment of women showed that none of the hypothesized factors were significantly associated. This may be related to a greater emphasis on promoting positive behaviors in the quality interventions than on eliminating negative ones, though this requires some investigation. Because we generally think of positive and negative treatment of women as being inversely related to each other and doing one would negate the other, it seems that this was not necessarily the case. Some additional analysis of the relationship between RMC practices and mistreatment of women behaviors may provide useful insight to clinicians, trainers and policy makers.

\section{Strengths and limitations}

A strength of this study is that it is one of the few that has explored prevalence of mistreatment of women through observation. Most studies conducted on mistreatment of women used client exit interviews to measure mistreatment of women, which may underestimate prevalence due to recall bias. The data collectors who observed providerclient interaction observation were clinicians experienced in BEmONC services, or independent consultants who worked in universities or other health facilities outside their permanent work stations.

Another strength of this study was that it covered both hospitals and health centers in the four major regions of Ethiopia, which strengthens its ecological validity. The study also has a number of limitations. Its main limitation is the cross-sectional design, which precludes any conclusion of causal effect. We found associations between some provider and facility-related factors and RMC but cannot conclude that these factors caused RMC. Another study limitation was the possible Hawthorne effect, in which providers will show acceptable behavior during service provision because they know that they are being observed. This effect usually diminishes with each observation and each provider was observed more than once. Also, we can not ignore the potential measurement error caused by differences in understanding among observers. To minimize the potential measurment error, highly experienced assessors who were national trainers of BEmONC training, who received 5 days of training for the observer role and were actively supervised. Lastly, the observation tool used in this study was not validated in Ethiopia as was the tool recently developed in Ethiopia [49]. However, the study team discussed each item in the tool with participants in the data collectors training. It was useful for the observation guides to collect information on both positive and negative behaviors.

\section{Conclusion}

MNH program managers and health professionals' educational institutions should consider the role of gender and profession on the practice of RMC services. More studies are needed to understand the individual, community, health provider and health facility related factors that affect experience of mistreatment of women in Ethiopia. Preservice education for the maternal health workforce (covers all cadre that work in maternity unit) needs to have RMC as a core area that deserves emphasis. Health care providers were uncomfortable allowing women to deliver other than lying down at their backs. $\mathrm{MOH}$ should condider strengthening the training in alternative birthing positions as part of inservice training and preservice education. In addition, inservice training as well as preservice education programs for health workers need to incorporate counselling and communication skills with women in labor. Making delivery beds available that allow alternative birth position in health facilites need to be prioritized. The study team also recommends $\mathrm{MOH}$ to consider the role of quality improvement approaches that incorporate providers's behavior on compassionate and respectful care needs to be implemented across facilites in Ethiopia. Moreover, $\mathrm{MOH}$ should establish or strengthen the exiting systems that foster accountability to the public and forms of redress when providers do not meet standards. Finally, the study team recommend health institutions should create greater awareness with the public on the levels of RMC that they should create systems to handle and address complaints.

\section{Abbreviations}

BEmONC: Basic Emergency Obstetrics and Newborn Care; Cl: Confidence interval; D\&A: Disrespect and abuse; MNH: Maternal and Newborn Health MOH: Ministry of Health; OR: Odds ratio; RMC: Respectful Maternity Care; SBA: Skilled Birth Attendant; SBM- $R^{\odot}$ : Standards Based Management and Recognition

\section{Acknowledgements}

We would like to acknowledge Judith Flurton (PhD), Linda Bartlet (PhD), Adrienne Kols, Cindy Geary, Muluneh Yigzaw and Reena Sethi for their critical review of the manuscript.

\section{Funding}

The funding to conduct this study was made possible by the generous support of the American people through the United States Agency for International Development (USAID) through Maternal and Child Health Integrated Program (MCHIP) under the cooperative agreement GHS-A-00-08-00002-000.

\section{Availability of data and material}

The datasets during and/or analyzed during the current study available from the corresponding author on reasonable request.

\section{Authors' contributions}

EDS designed the study, analyzed data and wrote the first draft of a manuscript. EB, YMK co-designed the study and contributed to manuscript writing. SAW, HFB, TB, AE, HG, MMW, FA, TvdA, JS contributed to data interpretation and manuscript writing. All authors read and approved the final manuscript.

Competing interests

The authors declare that they have no competing interests.

Consent for publication

Not applicable. 


\section{Ethics approval and consent to participate}

The study protocol was reviewed and approved by the National Ethics Review Committee (NERC) at the Ministry of Science and Technology in Ethiopia. The Johns Hopkins Bloomberg School of Public Health Institutional Review Board in Baltimore, Maryland, USA, indicated the study was exempt from oversight under U.S. legislation, 45 CFR 46.101 (b). All participants gave signed consent forms.

\section{Publisher's Note}

Springer Nature remains neutral with regard to jurisdictional claims in published maps and institutional affiliations.

\begin{abstract}
Author details
'Jhpiego, Addis Ababa, Ethiopia. ${ }^{2}$ Jhpiego, Baltimore, USA. ${ }^{3}$ Ethiopian Midwives Association, Addis Ababa, Ethiopia. ${ }^{4}$ Ministry of Health, Addis Ababa, Ethiopia. ${ }^{5}$ Department of Obstetrics, Leiden University Medical Center, Leiden, The Netherlands. 'Leeuwarden Medical Centre, Leeuwarden, The Netherlands. 'University Medical Centre Groningen, University of Groningen, Groningen, The Netherlands.
\end{abstract}

Received: 26 December 2016 Accepted: 3 May 2017

\section{Published online: 16 May 2017}

\section{References}

1. The prevention and elimination of disrespect and abuse during facilitybased childbirth: WHO statement. http://apps.who.int/iris/bitstream/10665/ 134588/1/WHO_RHR_14.23_eng.pdf. Accessed 2 Dec 2016.

2. Pulling back the curtain on disrespect and abuse: The movement to ensure respectful maternity care

3. Ethiopia Mini Demographic and Health Survey 2014. https://www.unicef org/ethiopia/Mini_DHS_2014_Final_Report.pdf. Accessed 2 Dec 2016

4. Committing to Child Survival: A Promise Renewed. https://www.unicef.org/ bangladesh/UNI195958.pdf. Accessed 2 Dec 2016.

5. Jewkes R, Abrahams N, Mvo Z. Why do nurses abuse patients? Reflections from South African obstetric services. Soc Sci Med. 1998;47(11):1781-95.

6. Kruk ME, Paczkowski M, Mbaruku G, de Pinho H, Galea S. Women's preferences for place of delivery in rural Tanzania: a population-based discrete choice experiment. Am J Public Health. 2009;99(9):1666-72.

7. Shiferaw S, Spigt M, Godefrooij M, Melkamu Y, Tekie M. Why do women prefer home births in Ethiopia? BMC Pregnancy Childbirth. 2013;13:5.

8. Bohren MA, Hunter EC, Munthe-Kaas HM, Souza JP, Vogel J, Gülmezoglu AM. Facilitators and barriers to facility-based delivery in low- and middleincome countries: a qualitative evidence syntesis. Reprod Health J. 2014;11:71.

9. Campbell OMR, Graham WJ. Strategies for reducing maternal mortality: Getting on with what works. Lancet (London, England). 2006;368(9543): 1284-99.

10. Bowser D, Hill K. BowsExploring evidence for disrespect and abuse in facility-based childbirth: report of a landscape analysis. In. Washington (District of Columbia): United States Agency for International Development; 2010.

11. Helath sector Transformation Plan 2015-2020. http://www.moh.gov.et/ documents/26765/0/Health+Sector+Transformation+Plan/5542a23a-9bc746a2-8c1f-8b32c2603208?version=1.0. Accessed 6 May 2017.

12. Basic Emergency Obstetric \& Newborn Care (BEmONC). Training Manual http://pdf.usaid.gov/pdf_docs/PA00JX4F.pdf. Accessed 2 Dec 2016.

13. Standards-Based Management and Recognition (SBM-R)—A Field Guide: A Practical Approach for Improving the Performance and Quality of Health Services. http://www.dhsc.edu.et/res/SBMR.pdf. Accessed 2 Dec 2016.

14. Kim YM, Banda J, Kanjipite W, Sarkar S, Bazant E, Hiner C, Tholandi M, Reinhardt S, Njobvu PD, Kols A, et al. Improving performance of Zambia Defence Force antiretroviral therapy providers: evaluation of a standardsbased approach. Glob Health Sci Pract. 2013;1(2):213-27.

15. Kols A, Kim YM, Bazant E, Necochea E, Banda J, Stender S. A standardsbased approach to quality improvement for HIV services at Zambia Defence Force facilities: results and lessons learned. AIDS (London, England). 2015;29 Suppl 2:S145-153.

16. Kim YM, Chilila M, Shasulwe H, Banda J, Kanjipite W, Sarkar S, Bazant E, Hiner C, Tholandi M, Reinhardt S, et al. Evaluation of a quality improvement intervention to prevent mother-to-child transmission of HIV (PMTCT) at Zambia defence force facilities. BMC Health Serv Res. 2013;13:345.
17. Necochea E, Tripathi V, Kim YM, Akram N, Hyjazi Y, da Luz VM, Otolorin E, Pleah T, Rashidi T, Bishanga D. Implementation of the Standards-Based Management and Recognition approach to quality improvement in maternal, newborn, and child health programs in low-resource countries. Int J Gynaecol Obstet. 2015;130 Suppl 2:S17-24.

18. Adams G, Gulliford MC, Ukoumunne OC, Eldridge S, Chinn S, Campbell MJ. Patterns of intra-cluster correlation from primary care research to inform study design and analysis. J Clin Epidemiol. 2004;57(8):785-94.

19. Getachew A, Ricca J, Cantor D, Rawlins B, Rosen H, Tekleberhan A, et al. Quality of care for prevention and management of common maternal and newborn complications: a study of Ethiopia's hospitals. Baltimore: Jhpiego; 2011.

20. Rosen HE, Lynam PF, Carr C, Reis V, Ricca J, Bazant ES, Bartlett LA. Direct observation of respectful maternity care in five countries: a cross-sectional study of health facilities in East and Southern Africa. BMC Pregnancy Childbirth. 2015;15(1):306.

21. Bohren MA, Vogel JP, Hunter EC, Lutsiv O, Makh SK, Souza JP, Aguiar C, Saraiva Coneglian F, Diniz AL, Tuncalp O, et al. The mistreatment of women during childbirth in health facilities globally: a mixed-methods systematic review. PLoS Med. 2015;12(6):e1001847. discussion e1001847.

22. U.S. Census Bureau: Census and Survey Processing System: Release 5.0. In.: U.S. Census Bureau, ICFI, and Serpro S.A.; 2012.

23. StataCorp. Stata Statistical Software: Release 13. College Station, TX: Stata Corp LP; 2013.

24. Peugh JL. A practical guide to multilevel modeling. J Sch Psychol. 2010; 48(1):85-112.

25. World Health Organization (WHO): Standards for improving quality of maternal and newborn care in health facilities. In.; 2016.

26. Bohren. Facilitators and barriers to facility-based delivery in low- and middle-income countries: a qualitative evidence synthesis Globally: A Mixed-Methods Systematic Review. PLoS Med. 2014;6(e1001847):12.

27. Jemal Yousuf MAaFS: Maternal health beliefs, attitudes and practices among Ethiopian Afar. In: Exchange on HIV/AIDS, Sexuality and Gender. 2011: 12-15. http://www.bibalex.org/Search4Dev/files/377648/216504.pdf. Accessed 10 Ded 2017.

28. Afsana K, Rashid SF. The challenges of meeting rural Bangladeshi women's needs in delivery care. Reprod Health Matters. 2001;9(18):79-89.

29. Kyomuhendo Grace Bantebya GB: Low use of rural maternity services in Uganda: impact of women's status, traditional beliefs and limited resources. Reproductive Health Matters. 2003;11(21):16-26.

30. Federal Democratic Republic of Ethiopia, Ministry of Health. Basic emergency obstetric and newborn care (BEmONC) training manual. Ethiopia Ministry of Health; 2013. http://pdf.usaid.gov/pdf_docs/PA00JX4F. pdf. Accessed 7 Nov 2016.

31. World Health Organization (WHO): Companion of choice during labour and childbirth for improved quality of care. In.; 2016.

32. McMahon SA, George AS, Chebet JJ, Mosha IH, Mpembeni RN, Winch PJ. Experiences of and responses to disrespectful maternity care and abuse during childbirth; a qualitative study with women and men in Morogoro Region, Tanzania. BMC Pregnancy Childbirth. 2014;14:268

33. Reem Hatamleh IASCHEtEoJWWMCS, Health Care for Women International, 34:6, 499-512, doi:10.1080/07399332.2012.680996.

34. Sandall J, Soltani H, Gates S, Shennan A, Devane D. Midwife-led continuity models versus other models of care for childbearing women. Cochrane Database Syst Rev. 2016:4:Cd004667.

35. Filby A, McConville F, Portela A. What prevents quality midwifery care? a systematic mapping of barriers in Low and middle income countries from the provider perspective. PLoS One. 2016;11(5):e0153391.

36. FMOH: Health Sector Transformation Plan 2015/16-2019/20. In. Edited by Health TFDRoEMo. Addis Ababa, Ethiopia: FMOH; 2015

37. Shimpuku Y, Patil CL, Norr KF, Hill PD. Women's perceptions of childbirth experience at a hospital in rural Tanzania. Health Care Women Int. 2013;34(6):461-81.

38. World Health Organization (WHO): WHO Safe Childbirth Checklist. In.; 2015.

39. Bowser, Hill: Exploring evidence for disrespect and abuse in facility-based childbirth: Report of a landscape analysis In.: USAID; 2010.

40. Tuncalp O, Were WM, MacLennan C, Oladapo OT, Gulmezoglu AM, Bahl R, Daelmans B, Mathai M, Say L, Kristensen F, et al. Quality of care for pregnant women and newborns-the WHO vision. BJOG. 2015;122(8):1045-9.

41. White Ribbon Alliance, Respectful Maternity Care: The Universal Rights of Childbearing Women (WRA 2011). In.

42. Abuya T, Ndwiga C, Ritter J, Bellows B, Binkin N, Charlotte WE: The effect of a multi-component intervention on disrespect and abuse during childbirth in Kenya. BMC pregnancy and childbirth 2015, 15(224):5-6. 
43. Asefa A, Bekele D. Status of respectful and non-abusive care during facilitybased childbirth in a hospital and health centers in Addis Ababa, Ethiopia. Reprod Health. 2015;12:33.

44. Okafor II, Ugwu EO, Obi SN. Disrespect and abuse during facility-based childbirth in a low-income country. Int J Gynaecol Obstet. 2015;128(2):110-3.

45. Sando D, Kendall T, Lyatuu G, Ratcliffe $H$, McDonald K, Mwanyika-Sando M, Emil F, Chalamilla G, Langer A. Disrespect and abuse during childbirth in Tanzania: are women living with HIV more vulnerable? J Acquir Immune Defic Syndr. 2014;67(Suppl 4):S228-234.

46. Kruk EM, Kujawski, Godfrey, Ramsey, Moyo, Freedman PL: Disrespectful and abusive treatment during facility delivery in Tanzania: a facility and Community survey. Health Policy and Planning 2014:1-8. doi:10.1093/ heapol/czu079.

47. Rominski SD, Lori J, Nakua E, Dzomeku V, Moyer CA: When the baby remains there for a long time, it is going to die so you have to hit her small for the baby to come out": justification of disrespectful and abusive care during childbirth among midwifery students in Ghana. Health policy and planning. 2016. doi:10.1093/heapol/czw114.

48. Bohren MA, Vogel JP, Tunçalp Ö, Fawole B, Titiloye MA, Olutayo AO, Oyeniran AA, Ogunlade M, Metiboba L, Osunsan OR, et al. "By slapping their laps, the patient will know that you truly care for her": A qualitative study on social norms and acceptability of the mistreatment of women during childbirth in Abuja, Nigeria. SSM Popul Health. 2016;2:640-55.

49. Sheferaw ED, Mengesha TZ, Wase SB. Development of a tool to measure women's perception of respectful maternity care in public health facilities. BMC Pregnancy Childbirth. 2016;16:67.

\section{Submit your next manuscript to BioMed Central} and we will help you at every step:

- We accept pre-submission inquiries

- Our selector tool helps you to find the most relevant journal

- We provide round the clock customer support

- Convenient online submission

- Thorough peer review

- Inclusion in PubMed and all major indexing services

- Maximum visibility for your research

Submit your manuscript at www.biomedcentral.com/submit 